\title{
Application of Nano Texturing on Multi-crystalline Silicon Solar Cells
}

\author{
Xianfang GOU ${ }^{1,2}$, Xiaoyan $\mathrm{LI}^{1}$, Shaoliang WANG ${ }^{3}$, Junlin HUANG ${ }^{2}$, , Jingwen $\mathrm{YU}^{2}$, \\ Xixi HUANG ${ }^{2}$, Su ZHOU $^{2}$, Qingsong HUANG ${ }^{2}$, Weitao FAN ${ }^{2}$
}

\author{
${ }^{1}$ Beijing University of Technology, 100124, Beijing, China \\ ${ }^{2}$ CECEP Solar Energy Technology (Zhenjiang) Co. Ltd, 212132, Zhenjiang, China \\ ${ }^{3}$ Beijing Jiaotong University, Beijing, China
}

crossref http://dx.doi.org/10.5755/j01.ms.24.2.17398

Received 09 January 2017; accepted 13 July 2017

\begin{abstract}
Nano texturing has been confirmed as an effective structure to improve the efficiency of multi-crystalline silicon solar cells by reducing optical loss. In this study, nano textured solar cells are fabricated by the Reactive Ion Etching (RIE) method based on a conventional production line. Several characterization methods are employed to evaluate the morphology, minority carrier lifetime, quantum efficiency and electricity performance of both nano textured and micro textured solar cells. The results show that nano textured solar cells have a maxiumum efficiency of $19.21 \%$ and an average efficiency that is $0.57 \%$ higher than that of micro textured solar cells. Thus, the RIE method is an effective way to manufacture nano textured solar cells. It can demonstrably improve the photoelectric conversion efficiency of massproduced solar cells and reduce the production cost, which is significant to the development of solar cell industry.

Keywords: nano texturing, reactive ion etching, silicon, solar cell.
\end{abstract}

\section{INTRODUCTION}

In the conventional solar cell process, anti-reflective microstructures (textures) are usually fabricated to improve conversion efficiency of solar cells [1-3]. Due to the uniform distribution of crystal orientation in monocrystalline silicon, small and uniform pyramid structure can be obtained by alkaline anisotropic etching $[4,5]$. The average reflectivity can be controlled below $10 \%$, which is helpful to the improvement of solar cell efficiency [6,7]. However, because the alkaline etching method can not be used in multi-crystalline silicon due to its random crystal orientation, the acid etching method is adopted as a substitution to fabricate the texture on multicrystalline silicon [8-10]. However, the reflectivity obtained by the acid etching method is around $20 \%$, leading to a decrease in efficiency [11-13]. Recently, several other etching methods, including metal-assisted chemical etching [14-16], reactive ion etching (RIE) [12, 17-19], plasma immersion techniques [20], and laser etching [21, 22], have been employed to prepare nano texture. By using these methods, the light trapping performance of solar cells can be significantly increased, which is benefit to the decrease of reflectivity. Among all these methods, RIE has been widely studied due to its advantages, such as a stable reaction, easy-to-control process and uniformity. In 2013, Jinsu Yoo et. al [23] achieved an efficiency of $17.4 \%$ by fabricating nano texture on conventional multi-crystalline silicon using the RIE method. Shiyong Liu et. al [24] using the RIE method and the matched process, achieved $0.51 \%$ higher efficiency than that of conventional solar cells. The short-circuit current can be easily increased by preparing nano texture in laboratory scale; however, this is harder to achieve at the mass production scale. In mass production, it is more difficult for the $\operatorname{SiN}_{x}$ thin film to cover the wafer uniformly because of the larger wafer size and smaller etch pits. Low-quality $\mathrm{SiN}_{\mathrm{x}}$ will influence the passivation performance and increase the recombination center. To solve this problem, the RIE method was employed to fabricate nano textured solar cells based on a conventional production line in this study. Passivation and anti-reflection film coating processes were also optimized to match the RIE process. Several characterization methods were employed to evaluate the differences in morphology, minority carrier lifetime, quantum efficiency and electricity performance between nano textured and micro textured solar cells.

\section{EXPERIMENT}

For this experiment, P-type mc-Si wafers with $1-3 \Omega \cdot \mathrm{cm}$ resistivity, a thickness of $200 \mu \mathrm{m}$ and dimensions of $156 \mathrm{~cm} \times 156 \mathrm{~cm}$ were used. The production process of micro texturing solar cells consisted of the following steps: acid etching (etching weight of $0.3-0.32 \mathrm{~g}$ ), high temperature phosphorus diffusion (sheet resistance of $85 \Omega-90 \Omega$ ), PSG removal, $\operatorname{SiN}_{\mathrm{x}}$ antireflection thin film depositing by PECVD (thickness of $85-90 \mathrm{~nm}$, refractive index of 2.05-2.10), screen printing and sintering. After acid etching, the RIE process was used to fabricate the nano texture on the wafer surface, a radio frequency (RF) power supply with a frequency of 13.56 MHz RF power is applied as the plasma source. Three kinds of gases including chlorine $\left(\mathrm{Cl}_{2}\right)$, sulfur hexafluoride $\left(\mathrm{SF}_{6}\right)$ and oxygen $\left(\mathrm{O}_{2}\right)$ are used as the reactant gas. Under the effect of RF power, the gases were changed into plasma and reacted with the surface of silicon, forming the nano texturing of solar cells. The morphology of the texture was characterized by SEM (Hitachi s4800). Reflectivity and

\footnotetext{
* Corresponding author. Tel.: 86-15152909848; fax: 86-85587711.

E-mail address: huangjunlin@cecsec.com (J. Huang)
} 
quantum efficiency were measured by a spectral response measurement system (EnliTech QE-R3011). Thickness and refractive index were measured by an ellipsometer (EnliTech SE400adv). Electrical performance of the solar cells was measured by HALM equipment (CestisPV-BI) under $25^{\circ} \mathrm{C}, 1000 \mathrm{~W} / \mathrm{m}^{2}$.

\section{RESULTS AND DISCUSSION}

\subsection{Characterization of morphology}
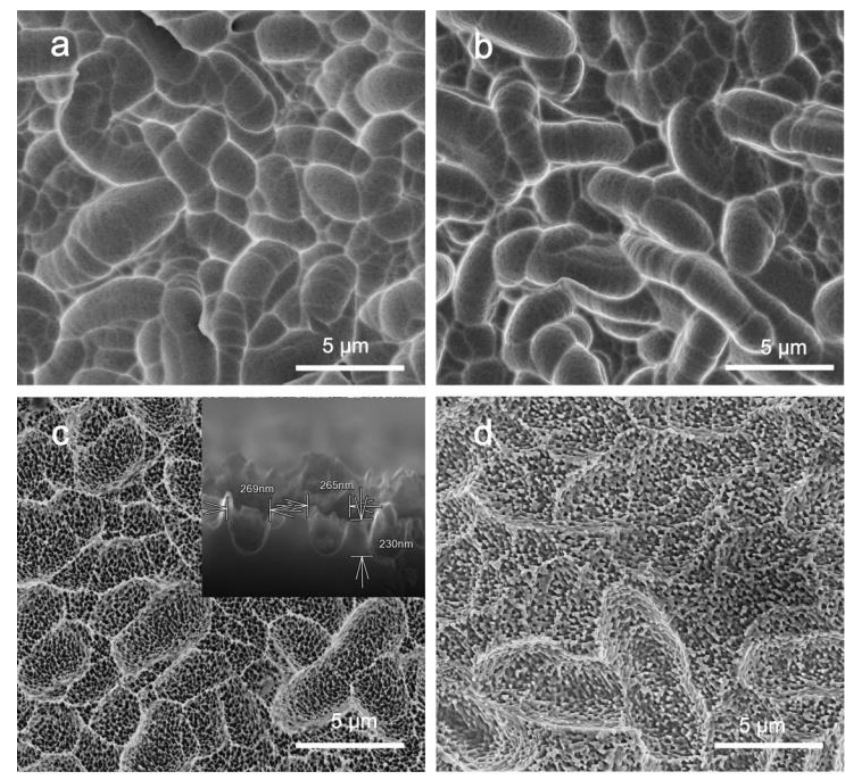

Fig. 1. $a$ and $b$-SEM pictures of conventional texturing before and after coating; $c$ and $d$-SEM pictures of nano texturing before and after depositing

Fig. 1 shows the SEM pictures of micro/nano textures before and after depositing. Fig. 1 a shows that uniformed etching pits were formed by acid etching; each of the pits is about $4-6 \mu \mathrm{m}$ long and $2 \mu \mathrm{m}$ wide. Fig. $1 \mathrm{c}$ shows the morphology of the nano texture, it can be seen that many small pits were formed inside the larger pits. Because the nano texture was fabricated by the RIE method on a microtextured base, it retained the morphology profile of micro pits, and formed many nano pits on the smooth surfaces of the micro texture. The cross section SEM picture (insert in Fig. $1 \mathrm{c}$ ) shows more details with higher magnification, the open size of the nano pits are around $260-270 \mathrm{~nm}$, the depth is around $230 \mathrm{~nm}$. Those nano pits can measurably reduce reflectivity and increase light absorption. During solar cell manufacture, the $\mathrm{SiN}_{\mathrm{x}}$ depositing is a very important process because it decided the passivation effect of the solar cells [26]. On one side, the nano texture can reduce the reflectivity of silicon wafer and increase the short current of solar cells. On the other side, it will also increase the surface area of silicon and destroy the uniformity of $\operatorname{SiN}_{x}$ film, leading to a decrease in open voltage. So it is very crucial to control the size of nano pits. Fig. $1 \mathrm{~b}$ shows the micro texture morphology after $\mathrm{SiN}_{\mathrm{x}}$ depositing; the $\mathrm{SiN}_{\mathrm{x}}$ thin film has uniformly covered the smooth surface of the micro texture, so there is no difference in the morphology before and after covering. Fig. $1 \mathrm{~d}$ displays the nano texture morphology after depositing. Comparison to Fig. $1 \mathrm{c}$ shows that the morphology has changed; because the pits in the nano texture are tiny, the morphology can easily be affected by SiNx depositing. It can be seen in Fig. $1 \mathrm{~d}$ that although some of the etch pits are small and deep, the surface is well covered by the SiNx thin film, which proving that the size of pits is very suitable for the solar cell.

\subsection{Reflectivity}

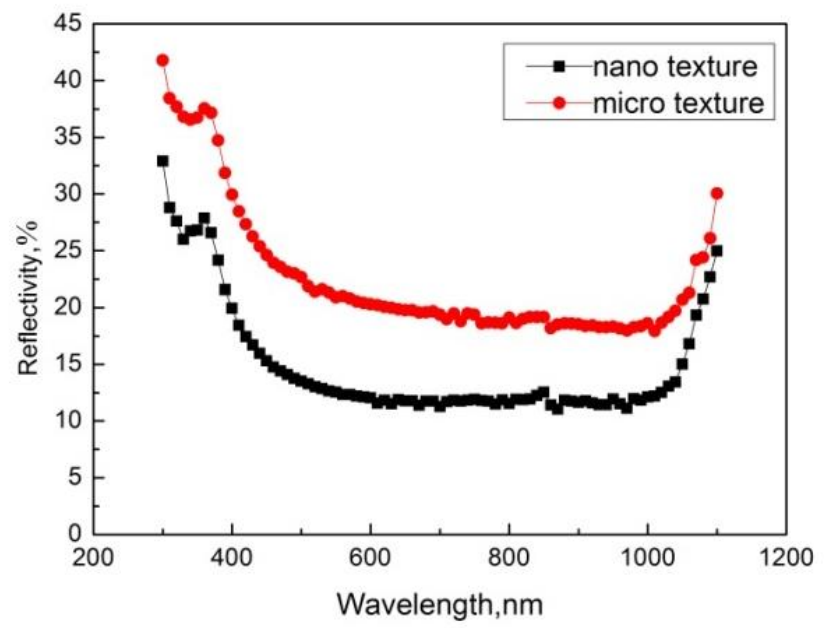

a

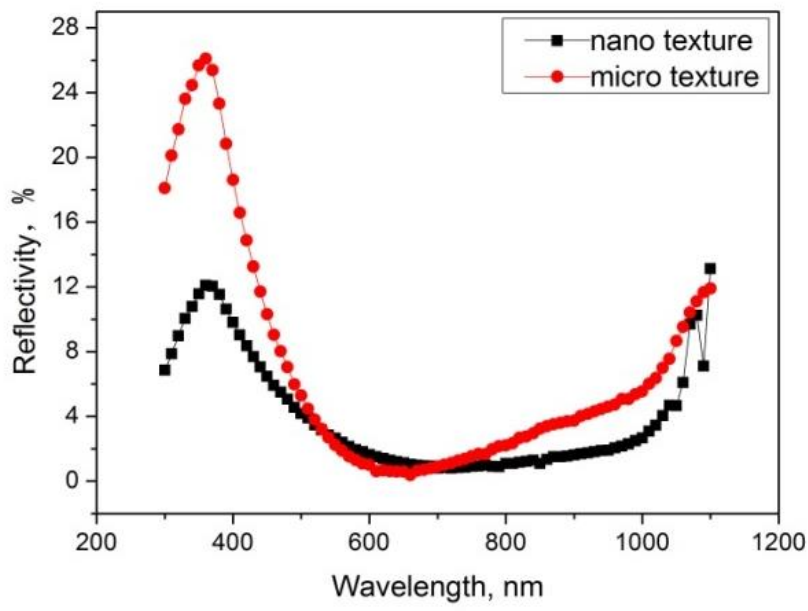

b

Fig. 2. a-reflectivity curve of conventional texturing and nano texturing; $b$-reflectivity curve of conventional texturing and nano texturing after depositing

Fig. 2 a displays the reflectivity curves of nano and micro textures, they are measured under wavelength between $300 \mathrm{~nm}$ to $1100 \mathrm{~nm}$ [25]. The average reflectivity during the set wavelength of the micro and nano textures was $22.69 \%$ and $14.91 \%$, respectively. For the whole wavelength range $(300-1100 \mathrm{~nm})$, the average reflectivity of the nano texture was $7.78 \%$ lower than that of the micro texture. Fig. 2 b shows the reflectivity curves after depositing; the average reflectivity of the micro and nano textures after depositing was $7.06 \%$ and $2.99 \%$, respectively. The reflectivity of the nano texture remained $4.07 \%$ lower than that of the micro texture. It can also be seen from Fig. $2 \mathrm{~b}$ that after $\mathrm{SiN}_{\mathrm{x}}$ depositing, the reflectivity of the nano texture was $2.69 \%$ at long wavelengths $(600-1000 \mathrm{~nm}), 1.72 \%$ lower than that of the micro texture, which was $4.41 \%$. At short wavelengths 
$(300-600 \mathrm{~nm})$, the reflectivity of the nano texture was $4.22 \%, 7.12 \%$ lower than that of the micro texture, which was $11.34 \%$. The results demonstrate that nano texturing has an advantage of reflectivity over micro texturing throughout the whole range of wavelengths.

\subsection{Quantum efficiency}

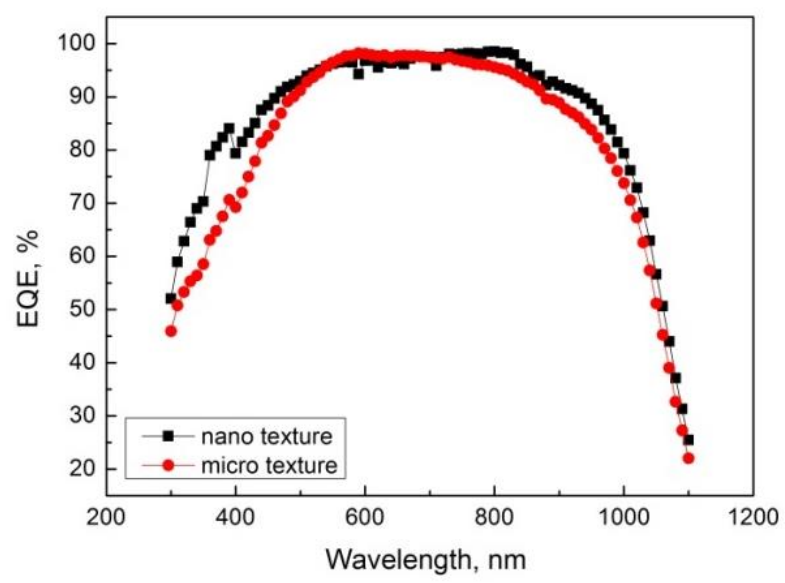

a

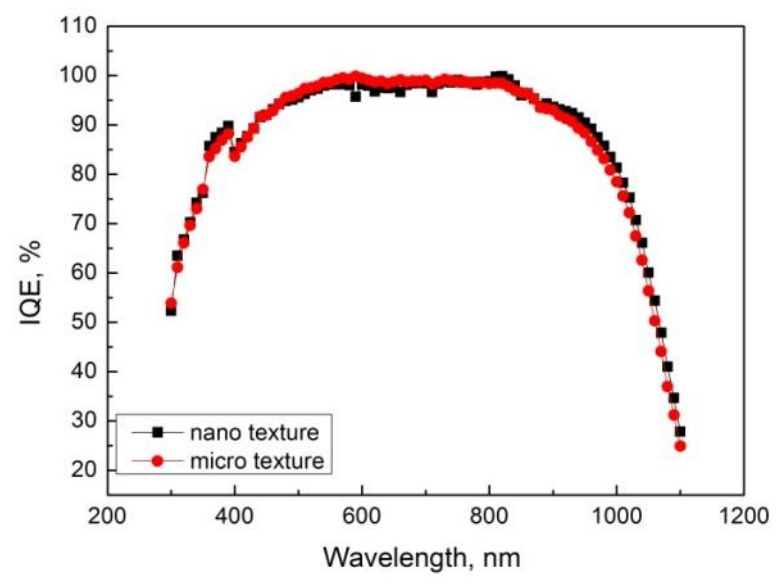

b

Fig. 3. EQE and IQE curve of conventional and nano texturing

Fig. $3 \mathrm{a}$ and $\mathrm{b}$ are the External Quantum Efficiency (EQE) and Internal Quantum Efficiency (IQE) curves of nano and micro textured solar cells. It can be seen from Fig. 3 a that the EQE of the nano texturing is higher than that of the micro texture in the short wavelength range. According to the reflectivity results, the advantage in EQE of nano texturing is more obvious at short wavelengths. The reflectivities are almost the same at the middle wavelengths. As Fig. $3 \mathrm{~b}$ shows, the IQE curves of the nano texture and micro texture are very similar at short and middle wavelengths; however, at long wavelengths, the IQE of nano textured solar cells is slightly higher than that of micro textured solar cells, illustrating that the passivation effect of nano texturing is better than that of micro texturing.

\subsection{Electrical properties}

The comparison of average electrical properties between nano texturing and micro texturing is shown in Table 1 . The tested quantity of nano and micro texturing solar cells are 1682 and 476 pieces respectively, the open circuit voltage $\left(\mathrm{V}_{\mathrm{oc}}\right)$ of nano textured solar cells is $2 \mathrm{mV}$ higher than that of conventional textured solar cells because the passivation effect of nano texturing was improved after thermal oxidation and the optimized PECVD process.

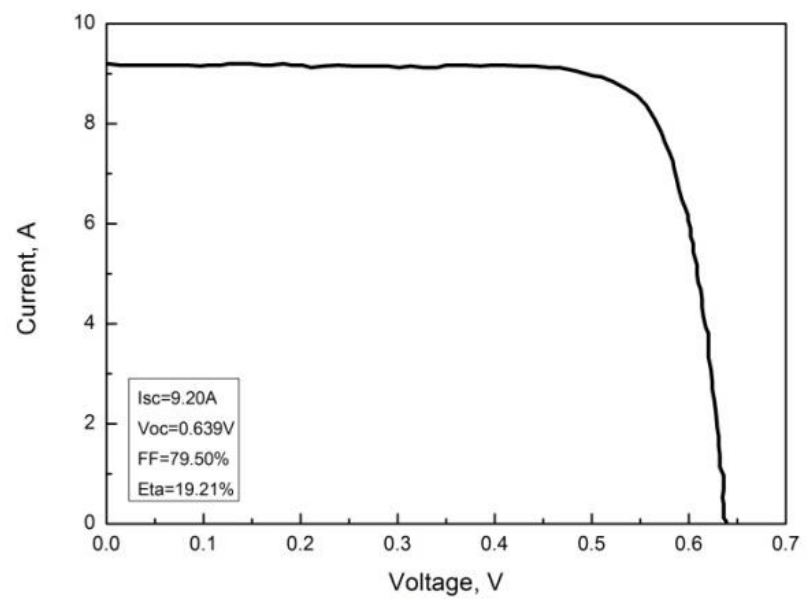

Fig. 4. I-V curve of nano texturing solar cell

This can also be explained by the IQE curve in Fig. 3 b. The short circuit current $\left(I_{\mathrm{sc}}\right)$ of a nano textured solar cell is $227 \mathrm{~mA}$ higher than that of micro textured solar cells, due to the decreased reflectivity and increased short wave response of the nano textured cell. The improvement of short circuit current makes a substantial contribution to the increased efficiency (Eta) of nano textured solar cells. Although the fill factor (FF) of a nano textured solar cell is lower than that of a micro textured solar cell, the average efficiency of nano textured solar cells is $0.57 \%$ higher than that of micro textured solar cells because of the increased short circuit current.

Table 1. Electrical properties parameter of conventional and nano texturing solar cells

\begin{tabular}{|l|c|c|c|c|c|}
\hline & Quantity, pcs & $V_{\mathrm{oc}}, \mathrm{V}$ & $I_{\mathrm{sc}}, \mathrm{A}$ & $\mathrm{FF}, \%$ & Eta, \% \\
\hline Nano texturing & 1682 & 0.634 & 9.087 & 79.64 & 18.86 \\
\hline Micro texturing & 476 & 0.632 & 8.818 & 79.92 & 18.29 \\
\hline
\end{tabular}

Moreover, the highest efficiency reached by nano textured solar cells was $19.21 \%$, with an open circuit voltage of $639 \mathrm{mV}$, a short circuit current of $9.2 \mathrm{~A}$ and a fill factor of $79.50 \%$, the relative error is below $1 \%$. The good results are attribute to the suitable size of nano pits (as shown in Fig. 4).

\section{CONCLUSIONS}

Nano textured solar cells were fabricated by the RIE method based on an optimized conventional mass production process. The reflectivity of nano texturing is lower than that of acid-etched micro texturing. After $\operatorname{SiN}_{x}$ depositing, the reflectivity of a nano textured solar cell was $2.99 \%, 4.07 \%$ lower than that of a micro textured cell. The passivation effect of nano textured solar cells improved after the optimized PECVD process. The IQE of nano textured solar cells was remarkably better than that of micro textured solar cells. As for the electrical properties, open circuit voltage increased by $2 \mathrm{mV}$, short circuit current was raised by $227 \mathrm{~mA}$, average efficiency increased by $0.57 \%$ and the maximum efficiency reached $19.21 \%$. According to a 
comprehensive analysis, nano texturing is able to considerably improve the conversion efficiency of multicrystalline solar cells, which is of great significance in reducing production costs and promoting the development of the photovoltaic industry.

\section{Acknowledgements}

The authors express the thanks to the National Natural Science Foundation of China under Grant No. 61575019; the Fundamental Research Funds for the Central Universities with the Grant No. 2017RC034, No. 2017RC015 and No. 2017JBZ105; the Doctoral Program of Higher Education No. 20130009130001 and Jiangsu Planned Projects for Postdoctoral Research Funds (1701072B).

\section{REFERENCES}

1. Glunz, S.W. New Concepts for High-Efficiency Silicon Solar Cells Solar Energy Materials \& Solar Cells $90(18-19)$ 2006: pp. 3276-3284.

https://doi.org/10.1016/j.solmat.2005.09.019

2. Shota, H., Takashi, M., Hideyuki, T., Yoshihiro, H. Influence of Texture Feature Size on Spherical Silicon Solar Cells Rare Metals 25(s1) 2006: pp. 115-120.

https://doi.org/10.1016/S1001-0521(07)60056-4

3. Macdonald, D.H., Cuevas, A., Kerr, M.J., Samundsett, C., Ruby, D., Winderbaum, S., Leo, A. Texturing Industrial Multicrystalline Silicon Solar Cells Solar Energy $76(1-3)$ 2004: pp. 277-283.

https://doi.org/10.1016/j.solener.2003.08.019

4. Seidel, H. Anisotropic Etching of Crystalline Silicon in Alkaline Solutions Journal of the Electrochemical Society 137 (17) 1990: pp. 3612-3626.

https://doi.org/10.1149/1.2086277

5. Motaweh, H.A. Alkali Anisotropic Chemical Etching of PSilicon Wafer In: Proceedings of the International Conference on Mechanics, Materials and Structural Engineering 2016: pp. $191-196$.

https://doi.org/10.2991/icmmse-16.2016.34

6. Panek, P., Lipiński, M., Dutkiewicz, J. Texturization of Multicrystalline Silicon by Wet Chemical Etching for Silicon Solar Cells Journal of Materials Science $40(6)$ 2005: pp. $1459-1463$.

https://doi.org/10.1007/s10853-005-0583-1

7. Haase, C., Stiebig, H. Thin-Film Silicon Solar Cells with Efficient Periodic Light Trapping Texture Applied Physics Letters 91 (6) 2007: pp. 0611161-0611164. https://doi.org/10.1063/1.2768882

8. Kulkarni, M.S., Erk, H.F. Acid-Based Etching of Silicon Wafers: Mass-Transfer and Kinetic Effects Journal of the Electrochemical Society 147 (1) 2000: pp. 176-188. https://doi.org/10.1149/1.1393172

9. Basu, P.K., Cunnusamy, J., Sarangi, D., Boreland, M.B. Novel Selective Emitter Process Using Non-Acidic Etch-Back for Inline-Diffused Silicon Wafer Solar Cells Renewable Energy 66 (3) 2014: pp. $69-72$.

https://doi.org/10.1016/j.renene.2013.11.062

10. El-Amin, A.A. Use of Etching to Improve Efficiency of the Multicrystalline Silicon Solar Cell by Using an Acidic Solution Silicon 2015: pp. 1-7.

https://doi.org/10.1007/s12633-015-9320-9

11. Ye, X., Zou, S., Chen, K., Li, J., Huang, J., Cao, F., Wang, X., Zhang, L., Wang, X.F., Shen, M. $18.45 \%$-Efficient MultiCrystalline Silicon Solar Cells with Novel Nanoscale PseudoPyramid Texture Advanced Functional Materials 24 (42) 2014: pp. $6708-6716$.

https://doi.org/10.1002/adfm.201401589
12. Chen, W.H., Hong, C.N. $0.76 \%$ Absolute Efficiency Increase for Screen-Printed Multicrystalline Silicon Solar Cells with Nanostructures by Reactive Ion Etching Solar Energy Materials \& Solar Cells 157 2016: pp. 48-54. https://doi.org/10.1016/j.solmat.2016.05.046

13. Huang, Z., Zhong, S., Hua, X., Lin, X., Kong, X., Dai, N., Shen, W. An Effective Way to Simultaneous Realization of Excellent Optical and Electrical Performance in Large-Scale Si Nano/Microstructures Progress in Photovoltaics Research \& Applications 23 (8) 2015: pp. 964-972. https://doi.org/10.1002/pip.2506

14. Huang, Z., Geyer, N., Werner, P., De Boor, J., Gösele, U. Metal-Assisted Chemical Etching of Silicon: A Review Advanced Materials 23 (2) 2011: pp. 285-298. https://doi.org/10.1002/adma.201001784

15. Chartier, C., Bastide, S., Lévy-Clément, C. Metal-assisted Chemical Etching of Silicon in HF-H $2 \mathrm{O} 2$ Electrochimica Acta 53 (17) 2008: pp. 5509-5516. https://doi.org/10.1016/j.electacta.2008.03.009

16. Um, H.D., Kim, N., Lee, K., Hwang, I., Hoon, S.J., Yu, Y.J., Duane, P., Wober, M., Seo, K. Versatile Control of MetalAssisted Chemical Etching for Vertical Silicon Microwire Arrays and Their Photovoltaic Applications Scientific Reports 5 2015: pp. $1-11$. https://doi.org/10.1038/srep11277

17. Ruby, D.S., Zaidi, S.H., Narayanan, S., Bathey, B., Yamanaka, S., Balanga, R. RIE-Texturing of Industrial Multicrystalline Silicon Solar Cells In: Proceedings of the Photovoltaic Specialists Conference 2002: pp. 399-403. https://doi.org/10.1109/PVSC.2002.1190477

18. Winderbaum, S., Reinhold, O., Yun, F. Reactive Ion Etching (RIE) as a Method for Texturing Polycrystalline Silicon Solar Cells Solar Energy Materials \& Solar Cells $46(31)$ 1997: pp. $239-248$. https://doi.org/10.1016/S0927-0248(97)00011-1

19. Chen, W.H., Lin, H.H., Hong, C.N. Improvement of Conversion Efficiency of Multi-Crystalline Silicon Solar Cells Using Reactive Ion Etching with Surface Pre-Etching Thin Solid Films 597 2015: pp. 50-56. https://doi.org/10.1016/j.tsf.2015.10.056

20. Cheung, N.W. Plasma Immersion Ion Implantation Laser \& Ion Beam Modification of Materials 1994: pp. 50-56.

21. Saito, M., Kimura, S. Laser-assisted Chemical Etching for Texturing Silicon Surface In: Proceedings of the SPIE Photonics Europe 2010: pp. 1-10. https://doi.org/10.1117/12.853764

22. Saxena, S.K., Kumar, V., Rai, H.M., Sahu, G., Late, R., Saxena, K., Shukla, A. K., Sagdeo, P.R., Kumar,R. Study of Porous Silicon Prepared Using Metal-Induced Etching (MIE): a Comparison with Laser-Induced Etching (LIE) Silicon 2014: pp. 1-6. https://doi.org/10.1007/s12633-014-9242-y

23. Yoo, J., Cho, J.S., Ahn, S.J., Gwak, J., Cho, A., Eo, Y.J., Yun, J.H., Yoon, K., Yi, J. Random Reactive Ion Etching Texturing Techniques for Application of Multicrystalline Silicon Solar Cells Thin Solid Films 546 (9) 2013: pp. 275-278. https://doi.org/10.1016/j.tsf.2013.02.045

24. Liu, S., Niu, X., Shan, W., Lu, W., Zheng, J., Li, Y., Duan, H., Quan, W., Han, W., Wronski, C.R. Improvement of Conversion Efficiency of Multicrystalline Silicon Solar Cells by Incorporating Reactive Ion Etching Texturing Solar Energy Materials \& Solar Cells 127 (4) 2014: pp. 21-26. https://doi.org/10.1016/j.solmat.2014.04.001

25. Aldosari, M, Sohrabpoor, H, Gorji, N.E. Optical Modeling of Graphene Contacted CdTe Solar Cells Superlattices \& Microstructures 92 2016: pp. 242-248. https://doi.org/10.1016/j.spmi.2016.02.023

26. Amrani, A.E., Bekhtari, A., Kechai, A.E., Menari, H., Mahiou, L., Maoudj, M. Efficient Passivation of Solar Cells by Silicon Nitride Vacuum 120 2015: pp. 95-99. https://doi.org/10.1016/j.vacuum.2015.04.041 